\title{
Population characteristics of Brueelia sp. on certain Indian Finches
}

\author{
Renu Saxena, H. B. Sharma, A ftab A hmad ${ }^{1}$, G aurav Arya ${ }^{1}$, Nayanci Bansal ${ }^{1}$, Archna R ashmi $^{1}$ \\ and A.K. Saxena ${ }^{1 *}$ \\ Department of Zoology, B.S.A. College, Mathura, INDIA \\ ${ }^{1}$ Department of Zoology, Government Raza Postgraduate College, Rampur-244901 (U.P.), INDIA \\ *Corresponding author. E-mail: akscsir@ rediffmail.com
}

\begin{abstract}
Five kinds of finches were examined during 2004-06. Two kinds of finches were found infested with ischnoceran lice, Brueelia sp. (Prevalence-20.5\%, mean intensity of infestation-4.7 and range of infestation, 1-23). The frequency distribution pattern of Brueelia sp. on Indian finches conformed to the negative binomial model. Sex ratio was skewed in favour of females and adults outnumbered the nymphs in natural population.
\end{abstract}

Keywords: Phthiraptera, Lice, Prevalence, Ischnocera, Amblycera, Mallophaga

\section{INTRODUCTION}

The population characteristics of Phthiraptera on selected Indian birds viz. domestic pigeons (Singh et al., 1998; Khan et al., 2009),common Myna (Chandra et al.; 90; Saxena et al., 2007), house crows (Beg et al., 2008), red avadavats (Gupta et al., 2007), bank Myna (Rajput et al., 2009), house sparrows, Indian parakeets, White breasted kingfishers (Saxena etal., 2007), and certain poultry (Khan et al., 2008) have been recorded during last 20 years. A survey of literature revealed that population level of Phthiraptera on common Indian finches deserved investigation. Present report furnishes information on the prevalence, intensity of infestation, nature of frequency distribution pattern and population composition of an ischnoceran louse, Brueelia sp. on certain common Indian finches.

\section{MATERIALS AND METHODS}

Two hundred five common Indian finches were examined during 2004-2006, in district Rampur and Mathura (India). After tying the legs, each bird was examined visually (with the help of magnifying torch). Uninfested birds were released in wild and infested hosts were subjected to delousing by the modified fair lsle method (Gupta et al., 2007). Fumigation method reportedly does not yield complete louse load (Clayton and Drown, 2001) but secures the life of bird. The head and body feathers of deloused birds were further examined manually to take out the remaining louse load. After delousing the birds were released in wild. Entire louse load was transferred to $70 \%$ alcohol and separated sex wise and stage wise. The prevalence, mean intensity, sample mean abundance, variance to mean ratio, exponent $(\mathrm{k})$ of the negative binomial distribution and index of discrepancy (D) were estimated with the help of software offered by Rozsa et al. (2000). The goodness of fit between the observed and the expected frequencies (negative binomial) was determined by the $X^{2}$ test.

\section{RESULTS}

As many as 205 finches were examined during 2004-06 to record the prevalence of phthirapteran ectoparasites (35 Leucosticte brandti, 38 Caprodocus erythrinus, 38 F ringilla sp., $30 \mathrm{C}$ ardolis sp. and 70 Acanthis sp.). None of the L. brandti, C. erythrinus and Fringila sp. were found infested with Phthiraptera. However, an ischnoceran louse belonging to genus Brueelia, occurred on some bird belonging to Cerdolis sp. and Acanthis sp. Prevalence of Brueelia sp. (Ischnoceran: Phthiraptera) remained $20.5 \%$, as only 42 birds were found infested. The mean intensity and median intensity remained 4.64 and 2.0 respectively. The sample mean abundance was $0.95(\mathrm{n}=205)$. The frequency distribution pattern was highly aggregated (hollow type) as 163 birds remained louse free. Eighteen birds carried single lice (Fig. 1). Presence of two lice was recorded upon six birds. Four birds had three lice. Three birds harboured five lice each. Six lice were recorded on two birds. Likewise, 13, 15, 17 and 20 lice were found present on one bird each. Lastly, one bird carried 23 lice (maximum number). The variance to mean ratio was greater than unity (10.42), indicating the over dispersion. The value of exponent of negative binomial (k) was computed as 0.09 . The index of discrepancy (D) was recorded as 0.906 (Table 1). The values of frequency distribution expected by negative binomial model did not differ from the observed frequencies $\left(X^{2}=32.67, P=0.05\right)$. In other words, the negative binomial was found to be a good fit in the frequency distribution pattern of Brueelia sp. on Indian 
Table 1. Showing population characterstics of B rueelia sp. on Indian finches.

\begin{tabular}{ll}
\hline Parameters & Brueelia sp. \\
\hline Sample size & 205 \\
Prevalence & $20.5 \%(\mathrm{n}=205)$ \\
Sample mean abundance & $0.95(\mathrm{n}=53)$ \\
Mean intensity & 4.64 \\
Median intensity & 2.0 \\
Range of infestation & $1-23(\mathrm{n}=205)$ \\
Variance to mean ratio of population & 10.42 \\
Exponent of negative binomial $(\mathrm{k})$ & 0.09 \\
Index of discrepancy (D) & 0.906 \\
Weather conforms to -ve Binomial & Yes \\
M:F & $1: 1.3$ \\
A:N & $1: 0.6$ \\
IN:IIN:IIIN & $1: 0.9: 0.7$ \\
\hline
\end{tabular}

common finches.

As many as 195 specimens of Brueelia sp. were collected from 42 infested finches, examined during present investigation. The population structure of Brueelia sp. on finches was recorded under five categories i.e. 1-5 lice, 6-10 lice, 11-15 lice, 16-20 lice and $>20$ lice (Table 2). An examination of table 2 indicates that females outnumbered the males in natural population, at all the levels of infestation. Moreover, sex ratio was more skewed in favour of females at lower levels of infestations. The overall ratio of males and females in natural population was $1: 1.3$. An examination of Table 2 further indicates that adult population dominated over nymphal population at lower levels of infestation. However, nymphs outnumbered the adults at highest level of infestation. The overall adult nymph ratio remained 1:0.6. The ratio of three nymphal instars (first, second and third) remained 1:0.9:0.7.

\section{DISCUSSION}

An examination of host parasite checklist of Phthiraptera furnished by Lakshminarayana (1979) revealed that only two kinds of finches (Acanthis flavirostris and Leucosticte brandti) have been subjected to investigation for recording the phthirapteran infestation. One species of genus Ricinus ( $R$. fringillae) have been listed from A. flavirostris. Another species of Ricinus ( $R$. brandti) has been reported from L. brandti. However, none of the finches examined during present studies carried Ricinus sp. Thus, occurrence of B rueelia sp. on Indian finches has been recorded for the first time. However, the world checklist of Phthiraptera (Price et al. 2003) indicates the presence of different species of Brueelia on different kinds of finches. The genus "Brueelia" is the most problematic taxon within Ischnocera (containing hundreds of species) and is desperately under need of a revision. Hence, the taxonomic categorization of Brueelia sp. collected from finches is still pending.

Studies revealed that prevalence of Brueelia sp. on common finches was quite low. As far as the prevalence of phthirapteran species on other birds is concerned, it ranged from $29-61 \%$ on blue rock pigeons, $13-68 \%$ on common Myna, $14-31 \%$ on house sparrows, $17-34 \%$ on Indian parakeets, $40 \%$ on Kingfishers, $11-52 \%$ on house crows, $21-36 \%$ on red avadavats and $31-48 \%$ on bank Myna (Chandra et al., 1990; Singh et al., 1998; Saxena et al., 2007; Gupta et al., 2007; Beg et al., 2008; Rajput et al., 2009; Khan et al., 2009).

Generally, the parasites exhibit aggregated distribution on their hosts; many host few parasites if any, while few hosts have a lot of them (Marshall, 1981). When the parasites are not randomly distributed among their hosts, variance of the population exceeds the mean. Rekasi et.al (1997) has advocated the use of negative binomial distribution to describe the pattern.

As far as intensity of infestation of different species of Phthiraptera on Indian birds is concerned, it has been reported to be 80.2 per bird on common Myna (Chandra et al., 1990), 18.4 to 182.5 per host on domestic pigeons (Singh et al., 1998), 11.0 to 27.0 per bird on house crows (Beg et al., 2008), 1.5 to 3.4 per bird on red avadavats (Gupta et al., 2007), 7.6 to 13.3 per bird on house sparrows, 13.8 to 21.8 per host on parakeets, 17.7 per bird on Kingfishers (Saxena et al., 2007) and 6.8 to 16.6 per host on bank Myna (Rajput et al., 2009) . Thus, in contrast to other birds the louse load born by Indian finches was too low as the sample mean abundance remained 0.95 . Sex ratio of the population of Brueelia sp. on Indian Table 2. Population composition of B rueelia sp. on 205 Indian finches.

\begin{tabular}{lcccccccccccccc}
\hline & & \multicolumn{1}{c}{$\begin{array}{c}\text { No. of } \\
\text { lice(classes) }\end{array}$} & Freq & Male & Female & Total & I N & II N & III N & Total & $\begin{array}{c}\text { Grand } \\
\text { Total }\end{array}$ & M: F & A: N & IN: IIN: IIIN N \\
\hline $1-5$ & 31 & 0.52 & 0.74 & 1.26 & 0.16 & 0.23 & 0.19 & 0.58 & 1.84 & $1: 1.44$ & $1: 0.46$ & $1: 1.40: 1.20$ \\
$6-10$ & 04 & 1.75 & 2.00 & 3.75 & 1.50 & 1.00 & 0.75 & 3.25 & 7.00 & $1: 1.42$ & $1: 0.87$ & $1: 0.67: 0.50$ \\
$11-15$ & 04 & 3.25 & 4.75 & 8.00 & 2.00 & 1.25 & 1.25 & 4.50 & 12.50 & $1: 1.46$ & $1: 0.56$ & $1: 0.63: 0.63$ \\
$16-20$ & 02 & 4.50 & 5.50 & 10.00 & 4.00 & 3.00 & 1.50 & 8.50 & 18.50 & $1: 1.22$ & $1: 0.85$ & $1: 0.75: 0.38$ \\
$>20$ & 01 & 6.00 & 7.00 & 13.00 & 3.00 & 4.00 & 3.00 & 10.0 & 23.00 & $1: 1.16$ & $1: 1.30$ & $1: 1.33: 1.00$ \\
\hline Total & 42 & 1.21 & 1.62 & 2.83 & 0.78 & 0.62 & 0.48 & 0.48 & 4.64 & $1: 1.33$ & $1: 0.63$ & $1: 0.87: 0.67$ \\
\hline
\end{tabular}




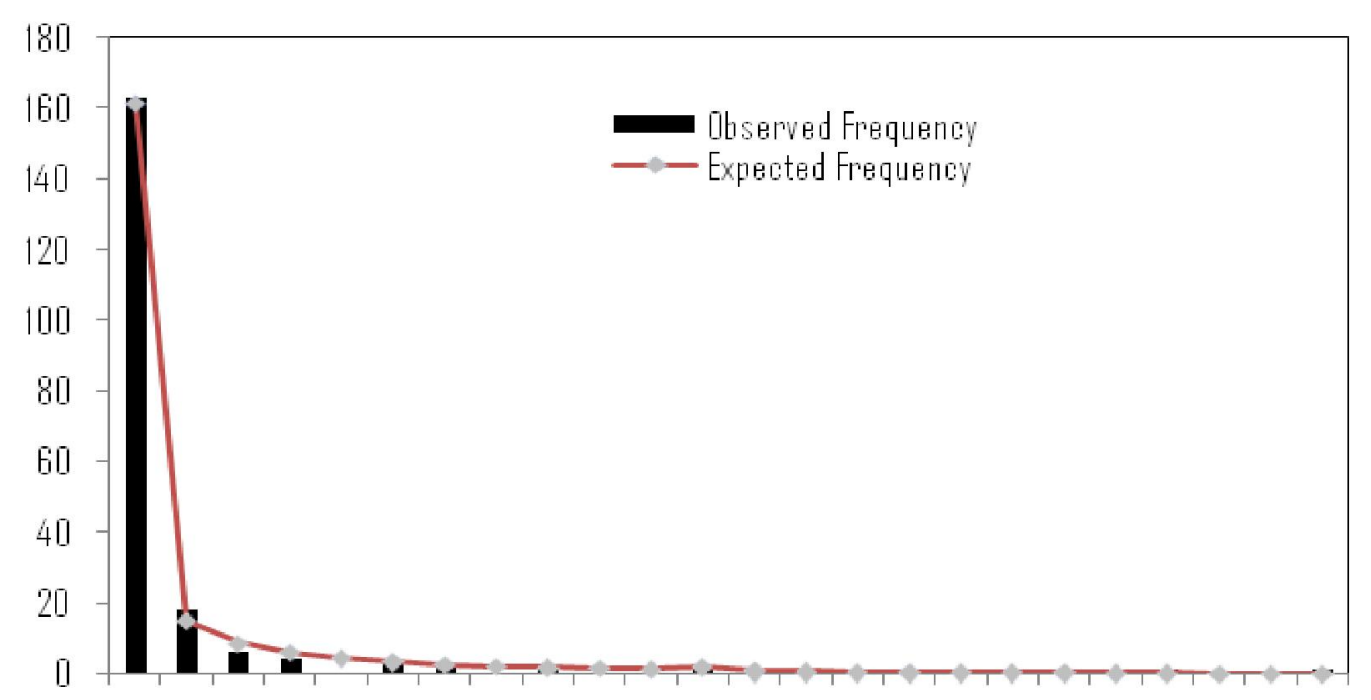

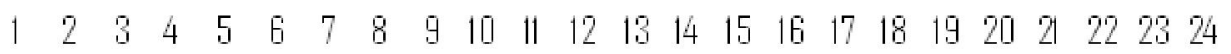

Fig 1. Showing frequency distribution of 195 Brueelia sp. on Indian finches, joined circles indicate the expected frequency for a negative binomial distribution.

finches conformed to the general trend observed in most of phthirapteran species. In phthirapterans, the females usually outnumber the males in natural population (Marshall, 1981). Reasons responsible for skewed sex ratios have been discussed elsewhere (Marshall, 1981; Gupta et al. 2007). The examination of adult nymphs ratio of any population provides some clues regarding the temporal stability of the population. The occurrence of few nymphs and more adults indicates declining population while the presence of more nymphs and few adults point out that population is expanding (Marshall, 1981). In case of finch louse, Brueelia sp., adult nymph ratio remained 1:0.63. However, it may be noted that lice population on avian hosts fluctuates seasonally, so adult nymph ratio of the population is bound to vary with time.

\section{ACKNOW LEDGEMENTS}

Authors are thankful to the Principal Govt. Raza P.G. College, Rampur and the Principal, B.S.A. College, Mathura, for providing laboratory facilities.

\section{REFERENCES}

Beg, S., Gupta, N., Kumar, S., Khan, V., Bhatnagar, S. and Saxena, A.K. (2008). Occurrence of Phthiraptera on the house crow, Corvus splendens (Passreiformes: Corvidae). Entomon, 33, 75-78.

Chandra, S., Agarwal, G. P., Singh, S. P. N. and Saxena, A. K. (1990). Seasonal changes in a population of M enacanthus eurysternus (Mallophaga: Amblycera) on the common Myna, Acridotheres tristis. International J ournal of Parasitology., 20, 1063-1065.

Clayton, D.H. and Drown D.M. (2001). Critical evaluation of five methods for quantifying chewing lice (Insecta: Phthiraptera). J ournal of Parasitology, 87, 1291-1300.
Gupta, N., Kumar, S., and Saxena, A. K. (2007). Prevalence and population structure of lice (Phthiraptera) on the Indian Red Avadavat. Zoolgical Science, 24:381-383.

Khan, V., Kumar, S., Gupta, N., Ahmad, A. and Saxena, A. K. (2008). Prevalence of phthirapteran ectoparasites on selected poultry in the district, Rampur (U.P.). Indian Veterinary J ournal. 85:447-448.

Khan, V., S. Kumar, N. Gupta, A. Ahmad and Saxena, A. K. (2009). Prevalence of lice in pigeons. Indian Veterinary J ournal, 86:531-532.

Lakshminaryana, K.V. (1979) A synoptic list of Mallophaga. Rec. Zool. Surv. India., 75:39-201.

Marshall, A. G. (1981). The ecology of ectoparasitic insects. Academic Press., London.

Price, R.D., Hellenthal, R.A., Palma, R.L., Johnson, K.P. and Clayton, D.H. (2003). The chewing lice: World checklist and biological overview. Illinois Natural History Survey special Publication., 1-501.

Rajput, S., Joshi, V. D., Gupta, N., Khan, V. and Saxena, A. K. (2009). Population dynamics of Phthiraptera on Indian Bank Myna, Acridother es ginginianus. Entomon., 34 (2):99- 102.

Rekasi, J., Rozsa, L. and Kiss, B.J. (1997). Patterns in the distribution of avian lice (Phthiraptera : Amblycera, Ischnocera). J ournal of Avian Biology. 28:150-156.

Rozsa, L., Reiczigel, J. and Majoros, G. (2000). Quantifying parasites in sample of hosts. J ournal of Parasitology. 86: 228-232.

Saxena A. K., Kumar, S., Gupta, N., Mitra, J. D., Ali, S. A. and Srivastava, R. (2007). Distribution pattern of phthirapterans infesting certain common Indian birds. J ournal of Parasitology., 93(4): 957-958.

Singh, S. K., Surman, Kumar, A. and Saxena, A. K. (1998). Population composition of four phthirapteran ectoparasites infesting blue rock pigeon Columba livia. J ournal of $P$ arasitic Disease., 22(2): 144-147. 